\title{
E-Wallet System for Bangladesh an Electronic Payment System
}

\author{
Mohammad Salah Uddin, Member, IACSIT, and Afroza Yesmin Akhi
}

\begin{abstract}
The purpose of this paper is to contribute to the design of e-wallets for Bangladesh, an Electronic Payment System (ETS). E-wallets are intended to replace the existing physical wallet, with its notes, coins, plastic cards, ATM cards and loyalty cards etc.

Now a day, the challenges of payment transactions were initially underestimated. Business via the internet and mobile telephony has so far been dominated by the methods of payment systems in traditional business. However, in light of advances in technology, traditional business models are increasingly coming up against their limits. e-wallet is a convenient, easy-to-use, secure payment system. It is flexible "Electronic payment system" with a number of payout and pay-in options via bank account and Credit/Debit cards.
\end{abstract}

Index Terms-E-Wallet, electronic payment system, microsoft wallet, bkash, NPS, POS, e-commerce.

\section{INTRODUCTION}

The digital revolution continues to transform most aspects of our daily life. In particular, the digital revolution has resulted in the vertical convergence of business channel capacities [1]. The digital revolution also continues to transform the public sector organizations and services. For instance, the DMP (Dhaka Metropolitan Police) receive GD (General Diary) application via online, Passport application, TIN (Tax Identification Number) registration, University admission etc. are also submitted through online. Other examples are Train tickets bought via mobile phones, online purchases, and social interactions made via SMS, emails and social networks. A next step in the digital revolution is the transformation of the time honored traditional physical wallet into the e-wallet.

\section{RELATED TECHNOLOGY IN BANGLADESH}

\section{A. Bkash}

Bangladesh's first complete mobile financial service provider, bKash Limited, a BRAC Bank subsidiary, launched its mobile banking operation in July 2011. bKash is designed to provide financial services via mobile phones to both the unbanked and the banked people of Bangladesh. The overall bKash value proposition is simple: a safe, convenient place to

Manuscript received January 24, 2014; revised May14, 2014.

Mohammad Salah Uddin is with Dipartimento di Informatica e Sistemistica Sapienza Universit'a di Roma, Rome, Italy (e-mail: akash.bangla@gmail.com).

Afroza Yesmin Akhi is with the Department of Computer Science and Engineering, East West University, Dhaka, Bangladesh (e-mail: ankhi.ayaz@yahoo.com). store money; a safe, easy way to make payments and money transfers. Fig. 1 shows the architecture of bkash.

The bKash mobile wallet is a VISA technology platform which is fully encrypted to ensure most secure transactions, will be the customer account into which money can be deposited and out of which money can be withdrawn or used for various services. Customers will be able to receive electronic money into their bKash accounts through salary, loan, domestic remittance, and other disbursements and eventually will cash out the electronic money from bkash authorized agents/ATM [2]. There are several cons of bkash, the service is not available everywhere in Bangladesh. There are four mobile operator in Bangladesh but till now all the mobile operators are not covered by bkash. The existence of bank account is totally forbidden in bkash system.

\section{B. National Payment Switch}

Bangladesh bank launched National Payment Switch (shows in Fig. 2) in 2012, a common platform for the country's commercial banks for electronic payments, which is going to revolutionize E-commerce in Bangladesh. Once all banks in Bangladesh join the NPS (National Payment Service), a customer using a credit or debit card of any bank will be able to draw cash from any ATM and POS (point of sales) in the country, and transaction costs will significantly go down as the transactions will be routed through the NPS instead of Visa, Master or Amex card networks abroad. Moreover, purchase and sale can be done with cards through the internet and web portals within the country [3]. NPS will facilitate easy access to funds, an increase in tax revenue, more flow of money in the economy, and financial inclusion. NPS is a common electronic payment platform to help banks and their clients make transactions in an easy and cost effective way. Individual payment platforms introduced by different banks will be abolished once all banks join the common platform.

\section{Internet Banking or Online Banking}

Online banking (or Internet banking or E-banking) allows customers of a financial institution to conduct financial transactions on a secured website operated by the institution, which can be a retail bank, virtual bank, credit union or building society.

To access a financial institution's online banking facility, a customer having personal Internet access must register with the institution for the service, and set up some password (under various names) for customer verification. The password for online banking is normally not the same as for [telephone banking]. Financial institutions now routinely allocate customers numbers (also under various names), whether or not customers intend to access their online 
banking facility. Customers numbers are normally not the same as account numbers, because number of accounts can be linked to the one customer number. The customer will link to the customer number any of those accounts which the customer controls, which may be cheque, savings, loan, credit card and other accounts. Customer numbers will also not be the same as any debit or credit card issued by the financial institution to the customer.

To access online banking, the customer would go to the financial institution's website, and enter the online banking facility using the customer number and password. Some financial institutions have set up additional security steps for access, but there is no consistency to the approach adopted.

Online banking facilities offered by various financial institutions have many features and capabilities in common, but also have some that are application specific. The common features fall broadly into several categories

1) A bank customer can perform non-transactional tasks through online banking, including -
a) viewing account balances
b) viewing recent transactions
c) downloading bank statements, for example in PDF format
d) viewing images of paid cheques
e) ordering cheque books
f) download periodic account statements
g) Downloading applications for M-banking, E-banking etc.

2) Bank customers can transact banking tasks through online banking, including -
a) Funds transfers between the customer's linked accounts
b) Paying third parties, including bill payments (see, e.g., BPAY) and telegraphic/wire transfers
c) Investment purchase or sale
d) Loan applications and transactions, such as repayments of enrollments
e) Register utility billers and make bill payments

3) Financial institution administration
a) Management of multiple users having varying levels of authority
b) Transaction approval process the process of banking has become much faster

4) Some financial institutions offer unique Internet banking services, for example

a) Personal financial management support, such as importing data into personal accounting software. Some online banking platforms support account aggregation to allow the customers to monitor all of their accounts in one place whether they are with their main bank or with other institutions.

The feature of Internet banking in Bangladesh is totally different. Most of the private bank provides internet banking service for customers. This is not pure internet banking, it's a demonstration only. Users/ customers just check their balance, show their account statement, money transfer is possible (within own account). Money transfer from one user to another user is not possible. Some banks provide mobile recharge and WI-max recharge facilities.

\section{SMS Banking}

SMS banking is a type of mobile banking, a technology-enabled service offering from banks to its customers, permitting them to operate selected banking services over their mobile phones using SMS messaging.

SMS banking services are operated using both push and pull messages. Push messages are those that the bank chooses to send out to a customer's mobile phone, without the customer initiating a request for the information. Typically push messages could be either Mobile marketing messages or messages alerting an event which happens in the customer's bank account, such as a large withdrawal of funds from the ATM or a large payment using the customer's credit card, etc.

Pull messages are those that are initiated by the customer, using a mobile phone, for obtaining information or performing a transaction in the bank account. Examples of pull messages for information include an account balance enquiry, or requests for current information like currency exchange rates and deposit interest rates, as published and updated by the bank.

Typical push and pull services offered under SMS banking:

1) Typical push services would include:

a) Periodic account balance reporting (say at the end of month)

b) Reporting of salary and other credits to the bank account

c) Successful or un-successful execution of a standing order

d) Successful payment of a cheque issued on the account

e) Insufficient funds

f) Large value withdrawals on an account

g) Large value withdrawals on the ATM or EFTPOS on a debit card

h) Large value payment on a credit card or out of country activity on a credit card.

2) Typical pull services would include:

a) Account balance enquiry

b) Mini statement request

c) Electronic bill payment

d) Transfers between customer's own accounts, like moving money from a savings account to a current account to fund a cheque

e) Stop payment instruction on a cheque

f) Requesting for an ATM card or credit card to be suspended

g) De-activating a credit or debit card when it is lost or the PIN is known to be compromised

h) Foreign currency exchange rates enquiry

i) Fixed deposit interest rates enquiry

\section{E-WALLET}

An electronic wallet is a program or web service that allows users to store and control their online shopping information, like logins, passwords, and shipping address 
and credit card details, in one central place. It also provides a convenient and technologically quick method for consumers to purchase products from any person or store across the globe. [4] Generally, the payment process is (before that a user must done their registration and collect their PIN):

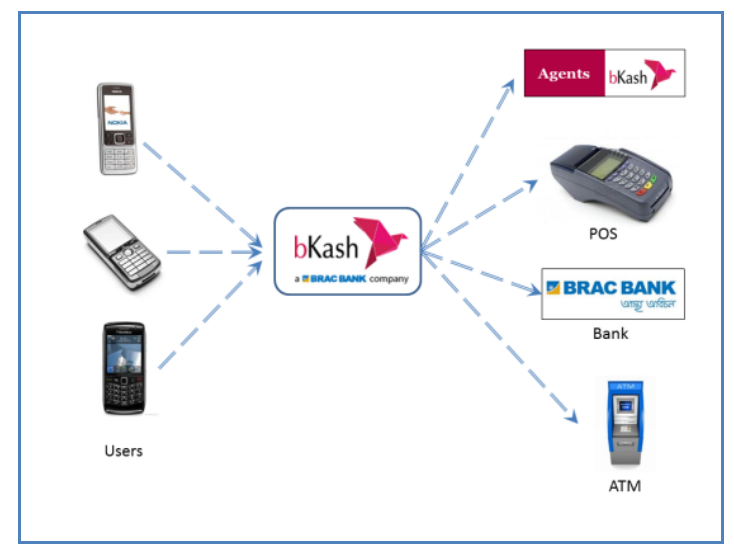

Fig. 1. The architecture of bkash.

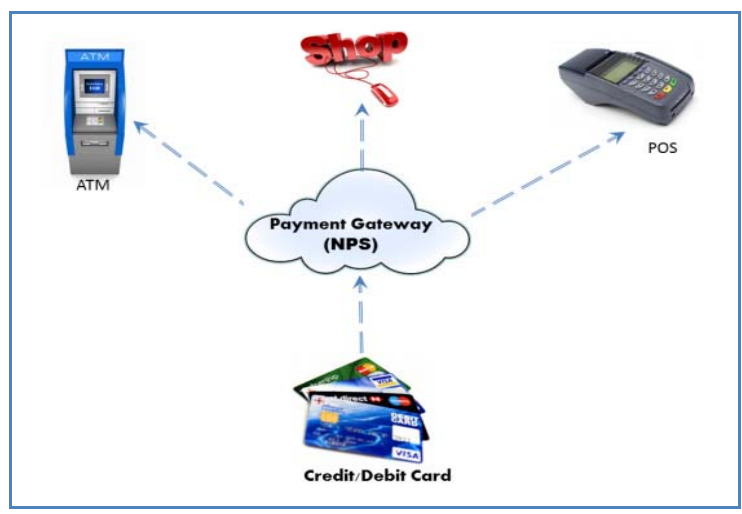

Fig. 2. National payment switch.

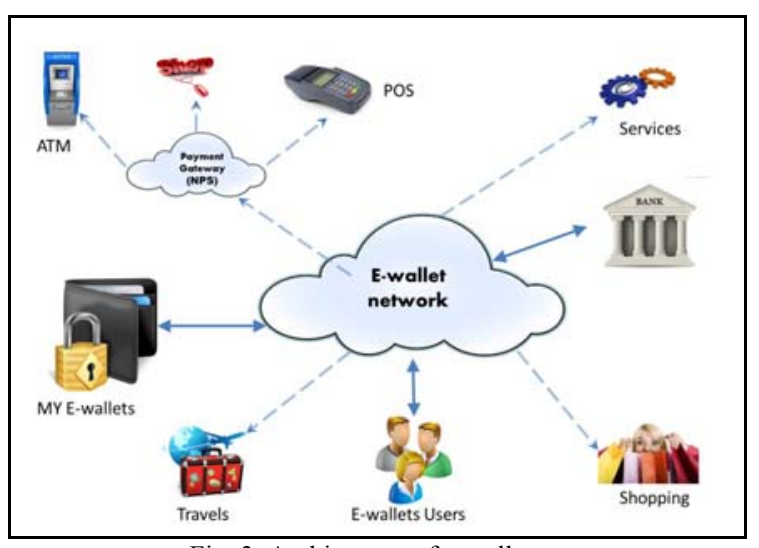

Fig. 3. Architecture of e-wallet.

1) User login their account using their ID and PIN

2) Choose their suitable payment method and perform the operation

The electronic wallet (e-wallet) provides all of the functions of today's wallet on one convenient smart card eliminating the need for several cads. The e-Wallet will also provide numerous security features not available to regular wallet carriers. e-wallet is a digital wallet which allows users to make electronic transactions quickly and securely [5].

In our proposed e-wallet, we directly linked our bank account to it. We assume that, it's a one kind of internet banking with more features such as purchase goods and service directly from our bank account, transfer money to others (e-wallet users), issuing e-checks, e-cash, e-pay-order etc. In other word, the whole banking services should be done by e-wallet. We linked our several bank accounts to e-wallet. We also link our credit/debit card; use them through e-wallet. e-wallet must be connected to National payment switch for getting more benefits. Fig. 3 shows the architecture of e-wallet.

e-wallets allow us to keep track of our billing and shipping information so that it can be entered with one click at participating merchants' sites.

The most common example of e-wallet system is Paypal. It is a fast way to pay and get paid online. Paypal allows people to send money without sharing financial information. People also have the flexibility to pay using their account balances, bank accounts, and credit cards. As of 2014, there are over 143 million active Paypal accounts, in 193 markets, and 26 currencies worldwide. PayPal allows for global commerce, through which it processes over 9 million payments each day. PayPal, which was bought by eBay for $\$ 1.3$ billion in late 2002, had contributed to 41 percent of eBay's revenues in 2013. It is nationally headquartered in San Jose, California, and internationally headquartered in Singapore. [6]

Another popular example of an e-wallet on the market is Microsoft Wallet. To obtain Microsoft Wallet, one needs to set up a Microsoft Passport. After establishing a Passport, a Microsoft e-wallet can be established. Then, e-wallets can be used for micro-payments. They also eliminate reentering personal information on the forms, resulting in higher speed and efficiency for online shoppers. Microsoft Passport consists of several services including, a single sign-in, wallet and kids passport services. A single sign-in service allows the customer to use a single name and password at a growing number of participating e-commerce sites. The shopper can use to make fast online purchases with a wallet service [7]. Kid's passport service helps to protect and control children's online privacy.

We should protect our wallet file with a password. With a password protected wallet we must enter the wallet's password before we can see the information on any of the cards/accounts in that wallet.

\section{A. Starting with e-Wallet}

When we start e-wallet for the first time, we are prompted to create a new wallet file to store our information in. When we're ready to add our own information, we can add new categories and cards to wallet and organize the information in a way that fits our needs.

e-wallet protects our wallet information in two ways:

1) By requiring a password before displaying any cards/ accounts in a password protected wallet.

2) By encrypting (making unintelligible) the information in cards/accounts in password protected wallets in our wallet file. This means that the information in the file is translated into a secret code so that it can't be read by any other program.

\section{B. Backup}

For extra safety, we encourage to take backups of our e-wallet files (as well as all of our important information). 
e-wallet will automatically make a backup of our wallet file each time we close e-wallet.

\section{Technology in e-Wallet}

A digital wallet has both a software and information component. The software provides security and encryption for the personal information and for the actual transaction. Typically, digital wallets are stored on the client side and are easily self-maintained and fully compatible with most e-commerce web sites. A server-side digital wallet, also known as a thin wallet, is one that an organization creates for and maintains on its servers. Server-side digital wallets are gaining popularity among major retailers due to the security, efficiency, and added utility it provides to the end-user, which increases their enjoyment of their overall purchase. The information component is basically a database of user-inputted information. This information consists of shipping address, billing address, payment methods (including credit card numbers, expiry dates, and security numbers), and other information.

\section{Benefits of e-Wallet}

1) Send and receive payments within Bangladesh.

2) Unlimited transfers.

3) Easy recurring payments and transfer.

4) Online and offline Shopping

5) Manage our account from our mobile phone.

6) Security for our bank account and credit card numbers.

7) Email or SMS notifications after transactions

8) We are in complete control.

9) Pull money into our e-wallet from any bank account.

10) Receive wired funds/transfers directly into our e-wallet.

11) Link any bank account within Bangladesh.

12) Transfer money from e-wallet to e-wallet without sharing personal account numbers.

\section{ISSUES FOR E-WALLET}

Main issue that should be taken care of for electronic payments system is Authentication which identifies buyer and also makes sure that person is who he/she claims to be. Used methods are i.e. digital signature, finger prints, two steps verification (like Gmail), password or smartcards etc. Data integrity which means, that there must be a way to verify that data is not changed during the transactions. Confidentially must also be preserved.

\section{A. Security for Online Systems}

Security of a customer's financial information is very important, without which online system could not operate. There are set up various security processes to reduce the risk of unauthorized online access to a customer's records, but there is no consistency to the various approaches adopted.

The use of a secure website has become almost universally adopted.

Though single password authentication is still in use, it by itself is not considered secure enough for online system in some countries. Basically there are two main systems for transaction security, secure socket layer and secure electronic Transaction.

\section{B. Secure Socket Layer (SSL)}

SSL is the widely used secure service system and is an important measure to establish trust between online seller and buyer [8]. Encryption and decryption allow secure transfer of information between an Internet browser and server. Data cannot be intercepted or changed during transmission. SSL also permits merchant identification through SSL server certificates. The SSL standard has been widely adopted because it is relatively simple and easy to use and does not place excessive demands on the average consumer's home PC. SSL has an over $90 \%$ share of security measures, about the same as credit cards among online payment systems. Until recently, SSL provided services exclusively for fixed networks. But as mobile networks are increasingly important e-commerce markets, SSL services for wireless devices have been developed.

\section{Secure Electronic Transaction (SET)}

SET is an alternative, more complex security system based on digital certificates and signatures [9]. SET needs specific software and is more difficult for cardholders to obtain and use, and despite the high level of security offered it has not gained widespread use.

\section{CONCLUSION}

The main discussion of the paper is "e-wallet" an Electronic payment System for Bangladesh, which replaced the traditional wallet that contains notes, coins, checks and Credit/Debit/ATM cards. The system will be developed if the Government of Bangladesh provides necessary support. Since it's a web-based system, any device can access the system via internet.

\section{REFERENCES}

[1] H. Li and J. D. Leckenby, "Examining the effectiveness of internet advertising formats," Internet Advertising: Theory and Research, $\mathrm{p}$. 528, 2007.

[2] BRAC Bank's bKash, PRWEB July 22, 2011.

[3] Bangladesh Bank opens gateway to e-commerce, The Daily Star, December 28, 2012.

[4] Safe Internet Banking. [Online]. Available: www.fdic.gov

[5] Digital wallet. [Online]. Available: http://www. en.wikipedia.org.

[6] Paypal. [Online]. Available: http:// www.paypal-media.com.

[7] D. Kosivr, Understanding Electronic Commerce: How Online Transactions Can Grow your Business, Microsoft Press, 1997.

[8] W. Xu, "E-commerce online payment security issues," Joint Hefei University Journal, 2000, vol. 3, pp. 23-25.

[9] J. Zhang, "Analyzes based on the SET agreement electronic commerce safety mechanism," Netinfo Security, 2006, vol. 10, pp. 9-11.

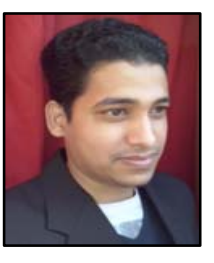

Mohammad Salah Uddin was a PhD student in Dipartimento di Informatica e Sistemistica Sapienza Universit'a di Roma, Rome, Italy. He previously works as a lecturer in the Department of Computer science and Engineering, Central Women's University, Dhaka, Bangladesh. He has been published several journal and international conference paper from his research work. $\mathrm{He}$ is a member of IACSIT and Software Engineering and Formal Method Research Group of East West University. He received his B.Sc in computer science and engineering from East West University, Dhaka, Bangladesh in 2012. He is interested in:- web service composition, semantic web service, knowledge representation, mobile apps, software engineering, software product line, modeling and verification.

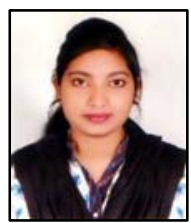

Afroza Yesmin Akhi was a B.Sc student in the Department of Computer Science and Engineering, East West University, Dhaka, Bangladesh. She is a member of Web Engineering Research Group, East West University. She is currently working towards web application development. She is also interested in Mobile apps. 